\title{
REFORMAS CONSERVADORAS E A “NOVA EDUCAÇÃO”: ORIENTAÇÕES HEGEMÔNICAS NO MEC E NO CNE*
}

\author{
Márcia Angela da Silva Aguiar ${ }^{1}$
}

\begin{abstract}
RESUMO: À luz da literatura da área que trata das reformas conservadoras e a nova educação implementadas no Brasil, o artigo problematiza as orientaçôes hegemônicas em debate, focalizando especialmente a atuação do Ministério da Educação (MEC) e do Conselho Nacional de Educaçáo (CNE) na formulação das políticas educacionais no período do Governo Michel Temer (2016-2018). O texto analisa as medidas governamentais direcionadas ao campo do currículo, da gestáo, da avaliação e da formação de professores, tendo como centralidade a Base Nacional Comum Curricular da Educação Infantil e do Ensino Fundamental e a Base Nacional Comum Curricular do Ensino Médio, e que implicam novas orientaçóes para os sistemas de ensino e instituiçôes educativas dos diferentes entes federados.
\end{abstract}

Palavras-chave: Reformas educacionais. Políticas educacionais do governo Michel Temer. Políticas curriculares. Base Nacional Comum Curricular. Formação de professores.

\section{CONSERVATIVE REFORMS AND "NEW EDUCATION": HEGEMONIC GUIDELINES IN MEC AND IN CNE}

\begin{abstract}
In the light of the literature concerning the conservative reforms and the "new education" implemented in Brazil, this article questions the hegemonic orientations under discussion, especially focusing on the activities of the Ministry of Education (MEC) and the National Education Council (CNE) in the formulation of educational policies in the period of Michel Temer's Government (2016-2018). The text analyzes the governmental measures directed to the field of curriculum, management, evaluation and training of teachers, having as centrality the Common National Curriculum of Early Childhood and Elementary Education and the Common National Curriculum of High
\end{abstract}

\footnotetext{
*Este artigo resulta de pesquisas desenvolvidas no Observatório de Políticas e Gestão da Educação do Programa de Pós-Graduação em Educação (PPGE)/Centro de Educação/Universidade Federal de Pernambuco.

${ }^{1}$ Universidade Federal de Pernambuco - Recife (PE), Brasil. E-mail: marciaangelaaguiar@gmail.com DOI: 10.1590/ES0101-73302019225329
} 
School and that they imply new orientations for the educational systems and institutions of the different federated entities.

Keywords: Educational reforms. Michel Temer's government educational policies. Curriculum policies. Common National Curriculum. Teacher training.

\section{REFORMAS CONSERVADORAS Y LA "NUEVA EDUCACIÓN": ORIENTACIONES HEGEMÓNICAS EN EL MEC Y EN EL CNE}

RESUMEN: A la luz de la literatura del área que trata de las reformas conservadoras y la "nueva educación", implementadas en Brasil, el artículo problematiza las orientaciones hegemónicas en debate, enfocando especialmente en la actuación del Ministerio de Educación (MEC) y del Consejo Nacional de Educación (CNE) en la formulación de las políticas educativas en el período del gobierno de Michel Temer (2016-2018). El texto analiza las medidas gubernamentales dirigidas al campo del currículo, de la gestión, de la evaluación y de la formación de profesores, teniendo como centralidad la Base Nacional Común Curricular de la Educación Infantil y de la Enseñanza Fundamental y la Base Nacional Común Curricular de la Enseñanza Media, y que implican nuevas orientaciones para los sistemas de enseñanza y las instituciones educativas de los diferentes entes federados.

Palabras clave: Reformas educativas. políticas educativas del gobierno de Michel Temer. Políticas curriculares. Base Nacional Común Curricular. Formación de profesores.

\section{Introdução}

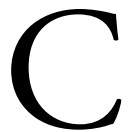

omo é plenamente reconhecido, na década de 1990, o fenômeno da globalizaçáo implicou profundas mudanças nas relaçóes sociais e trouxe impactos na capacidade de o Estado-naçáo implementar políticas estatais garantidoras de direitos sociais (ANDERSON, 1995; AFONSO, 2001; SANTOS, 2002; DALE, 2010; BALL, 2002). Em vários países, reformas foram anunciadas como forma de garantir governabilidade e de superar a crise do Estado de bem-estar social. O receituário para superar a crise consistiria na instituição de um Estado "diminuído em sua base social, mas burocraticamente eficaz para servir o capital” (BORON, 1994, p. 81).

O Brasil também realizou, em 1995, no governo do presidente Fernando Henrique Cardoso (FHC), do Partido da Social Democracia Brasileira (PSDB), uma reforma de Estado (BRESSER PEREIRA, 1998) que alterou o 
padrão de intervenção estatal, com repercussôes nas políticas públicas, inclusive nas políticas educacionais.

Com o propósito de modernizar o país, FHC implementou reformas no aparelho do Estado e nas políticas vigentes declaradamente visando reduzir o custo Brasil, superar a crise econômica e estabelecer as condiçóes para a inserção do país na economia globalizada (CARDOSO, 1998). Essas reformas atingiram as esferas pública e privada, com privatizaçóes de empresas estatais e abertura da economia e das importaçôes.

No campo da educação, o governo introduziu várias mudanças ${ }^{1}$ : a criação do Fundo de Manutenção e Desenvolvimento do Ensino Fundamental e de Valorização do Magistério (FUNDEF), a implantação do Sistema de Avaliação da Educação Básica (SAEB), a reforma curricular com o desenho dos Parâmetros Curriculares Nacionais (PCNs), o aprimoramento das informaçóes do Censo Educacional e a aprovação da Lei de Diretrizes e Bases da Educação Nacional (BRASIL, 1996; SAVIANI, 1997). Nesse período de governo (1995-2002), "a reforma modernizadora da educação superior ganhou força e as ideias neoliberais se materializaram em políticas e num quadro legal-burocrático coerente com as novas configuraçôes" (DIAS SOBRINHO, 2002, p. 76).

Ainda nesse contexto, Pinto (2002) observa, ao fazer um balanço do financiamento da educaçáo, que "a diretriz mestra do governo [...] foi a de que os recursos existentes são suficientes, cabendo apenas otimizar a sua utilização" (PINTO, 2002, p. 108). Referindo-se ao governo federal em relação ao Plano Nacional de Educação (PNE) 2001-2010 (BRASIL, 2001), destaca:

A postura adotada pelo Executivo diante do projeto aprovado pelo Congresso Nacional: vetar todos os mecanismos que viabilizariam financeiramente, sem um comprometimento maior da qualidade, o atendimento das metas ali estabelecidas. Assim, de uma forma geral, foram vetados todos os itens que implicassem um aporte adicional de recursos, por parte do governo federal (BRASIL, 2001, p. 123).

Ao examinar os itens vetados que requeriam recursos adicionais do executivo federal, o autor conclui seu estudo afirmando que "este governo será lembrado como aquele que gastou $4 \%$ do PIB com ensino e $8 \%$ do PIB com juros e encargos da dívida pública" (BRASIL, 2001, p. 108).

Fernando Henrique Cardoso foi substituído por Luiz Inácio Lula da Silva, do Partido dos Trabalhadores (PT), um líder popular de esquerda, eleito em 2002, em sua quarta tentativa para a presidência da República. A gestão Lula da Silva foi caracterizada, sobretudo, pela política de distribuição da renda, com aumento real do salário mínimo ( $52 \%$ nos oito anos de governo), pela reduçáo da desigualdade social com aumento das despesas sociais do Estado, ampliação do 
Programa Bolsa Família, entre outros (POCHMANN, 2017), o que levou o Brasil a não mais integrar o Mapa da Fome ${ }^{2}$.

No fim do governo Lula da Silva, irrompeu no cenário econômico internacional a crise financeira fiscal de 2008, considerada a maior crise do capitalismo neoliberal desde a de 1929, originada no interior do capitalismo rentista nos Estados Unidos. Os efeitos dessa crise tiveram maior impacto no Brasil, no governo subsequente, de Dilma Rousseff ${ }^{3}$, primeira mulher eleita presidente do país, em 2011.

Dilma Rousseff prosseguiu com a política econômica do governo Lula da Silva, enfrentou muitas dificuldades de ordem político-econômica, tendo sido reeleita no acirrado pleito presidencial de 2014. Cabe ressaltar que ao longo da sua gestão foram implementadas medidas de políticas que desagradaram vários grupos sociais, especialmente as elites brasileiras que elevaram o tom das críticas ao governo.

Entre as medidas políticas do governo Dilma Rousseff, pode-se admitir como um dos principais destaques, pelo impacto na educação brasileira, a sanção sem vetos do PNE 2014-2024, fruto de ampla discussão na sociedade brasileira e no Congresso Nacional. Diferentemente do que ocorreu com o PNE anterior (BRASIL, 2001), quando Fernando Henrique Cardoso vetou as principais metas relacionadas ao financiamento, o Plano sancionado pela presidenta Dilma Rousseff, considerado por Dourado (2017, p. 176) como "epicentro das políticas de Estado para a educação brasileira", incorporou em suas metas o percentual de $10 \%$ do produto interno bruto (PIB) a ser destinado à educação brasileira. Tal fato significou um extraordinário avanço para a redução da desigualdade educacional.

Contudo, dado o acirramento da crise política instalada no país, no dia 31 de agosto de 2016, Dilma Rousseff foi afastada definitivamente da presidência pelo Congresso Nacional, sob o argumento controverso de que fora condenada pela prática de crime de responsabilidade, especialmente pela suposta prática das chamadas pedaladas fiscais. Tal decisão provocou inúmeras polêmicas no país, não só nos meios jurídico-políticos, mas em todas as esferas da sociedade brasileira (SAVIANI, 2018).

Com o impeachment da presidenta Dilma Rousseff, encerra-se um ciclo de poder, iniciado em 2003, com políticas públicas permeáveis às demandas da sociedade civil, e retomam-se, com o governo Michel Temer do Movimento Democrático Brasileiro (MDB), as linhas mestras do projeto político neoliberal interrompido pela vitória eleitoral do presidente Lula da Silva.

Em síntese, pode-se afirmar que, no campo educacional, ao longo dos governos Lula da Silva e Dilma Rousseff, muitos avanços podem ser registrados, tanto na educação básica como na superior: os investimentos cresceram e atingiram todas as etapas da educação pública, cresceu o número de jovens que ingressaram no ensino médio com a idade certa, aumentou o acesso ao ensino superior, houve interiorização das universidades, os profissionais da educação ganharam 
o piso salarial. Além disso, realizaram-se as conferências nacionais da educação de 2010 e 2014 (Conae 2010 e Conae 2014), impulsionadas pela mobilização da sociedade civil e da sociedade política em prol da garantia do direito à educação pública, gratuita, laica e de qualidade referenciada pelo social. Tais conferências foram decisivas para a instituição do Fórum Nacional de Educação (FNE) (BRASIL, 2017b), para a formulação do PNE 2014-2024 e para a definição de marcos institucionais do Sistema Nacional de Educação (GRACINDO, 2010; CURY, 2009; DOURADO; OLIVEIRA, 2018).

Todavia, essas políticas de educação foram duramente atingidas com as reformas conservadoras implementadas pelo governo de Michel Temer, que assumiu a presidência interinamente em maio de 2016 e de forma definitiva a partir de agosto do mesmo ano. $\mathrm{O}$ item que segue vai tratar da agenda do governo Michel Temer e analisar as repercussóes de suas decisóes políticas e econômicas para a educação brasileira.

\section{Reformas conservadoras e a Nova Educação: prenúncios e incidências nas políticas curriculares e na gestão educacional}

De acordo com Pochmann (2018 apud NASSIF, 2018), "o neoliberalismo do governo Temer trouxe a nova segregação social":

No governo Lula (2003-2010), a taxa de pobreza caiu 50,3\%, uma vez que foi reduzida de $33,2 \%$ do conjunto da população, em 2002, para 16,5\%, em 2010. No governo Dilma (2011-2016), a taxa de pobreza seguiu a trajetória de queda em 39,4\% acumuladamente entre os anos de 2010 (16,5\% da população) e de 2015 ( $10 \%$ da população). Mesmo com esse significativo sentido de queda na taxa de pobreza, a população mais vulnerável seguiu, ainda, focada, nos brasileiros não brancos, mulheres e crianças, bem como as pessoas de menor escolaridade. Com o governo Temer, todavia, o crescimento da pobreza terminou expondo à vulnerabilidade da segregação social, justamente os estratos de brasileiros brancos, homens, adultos e com maior escolaridade. Entre os anos de 2016 e 2017, por exemplo, a pobreza subiu $5 \%$ no conjunto dos brasileiros (adicional de 3 milhóes de pessoas) (POCHMANN, 2018 apud NASSIF, 2018).

A principal medida econômica do presidente Michel Temer foi a Proposta de Emenda Constitucional 95/2016 (BRASIL, 2016), denominada de PEC dos Gastos. Encaminhada pelo governo, a PEC determina que, a partir de 2018, as despesas federais só poderão aumentar de acordo com a inflação acumulada conforme o Índice Nacional de Preços ao Consumidor Amplo (IPCA). O Congresso Nacional promulgou a Emenda Constitucional 95/2016, que limita por 
20 anos os gastos públicos (CÂMARA DOS DEPUTADOS, 2016). Essa PEC atinge todas as esferas da administração pública e impacta fortemente as políticas educacionais, sobretudo as decorrentes da aprovação do PNE 2014-2024.

Para o Ministério da Educação, o presidente interino Michel Temer nomeou Mendonça Filho (Deputado Federal do Democratas, DEM/PE), cujas iniciativas de gestão redirecionaram as políticas e açôes desse órgáo, rompendo com a perspectiva entáo vigente de participaçáo de setores da sociedade na definiçáo dos principais programas ministeriais, tônica da ação governamental nos períodos de gestão dos presidentes Lula da Silva e Dilma Rousseff.

As primeiras iniciativas do novo governo evidenciam uma inflexão nas relaçôes do executivo federal com o Fórum Nacional de Educação (FNE) e com o CNE, instâncias relevantes para a implementação das políticas de educação no país. Foram exaradas as ediçôes do Decreto Executivo de 26 de abril de 2017 e da Portaria no 577, de 27 de abril de 2017, que retiraram do FNE sua base de representaçáo social e descaracterizaram a configuração da $\mathrm{CNE}$, prevista para ocorrer em 2018 (BRASIL, 2017a).

Essa ação ministerial que até retirou a coordenação do Fórum da Confederação Nacional dos Trabalhadores em Educação (CNTE), escolhida pelo colegiado, acarretou a reação imediata das entidades da sociedade civil que optaram pela saída coletiva do FNE e instituíram o Fórum Nacional Popular de Educação (FNPE), com a responsabilidade de organizar a Conferência Nacional Popular de Educação 2018 (CONAPE 2018) e de "exigir o cumprimento dos planos nacional, estaduais, distrital e municipais de educação, contribuindo sempre para a sua análise e aperfeiçoamento numa luta permanente pela educação pública democrática" (FNPE, 2018).

O governo federal também interferiu na composição do CNE, principal órgáo normativo da educação brasileira, revogando o decreto da presidenta Dilma Rousseff, que nomeou os novos conselheiros do CNE, considerando a consulta às associaçóes e instituiçóes pertinentes (Decreto de 27 de junho de 2016). Ao agir dessa forma, o executivo federal procurava adequar a estrutura normativa do Conselho à nova perspectiva do projeto político governamental que se desenhava naquele contexto.

De fato, interessava ao governo que o CNE tivesse uma postura favorável às propostas e às açōes do MEC que, por lei, deveriam tramitar nessa instância. Constata-se que o maior interesse da nova gestão do MEC estava voltado à aprovação da Base Nacional Comum Curricular (BNCC) para a educação básica (AGUIAR, 2018). Tal postura não surpreende os estudiosos do campo, tendo em vista que a educação básica tem sido alvo de interesses de grupos nacionais e internacionais desde que ela entrou na órbita dos negócios lucrativos (FREITAS, 2014; ADRIÃO; PERRONI, 2018; BERNARDI, L.; UCZAK; ROSSI, 2018). 
Desde 2013, o denominado Movimento pela Base Nacional Comum $(\mathrm{MBNC})^{4}$, que se define como "um grupo não governamental de profissionais da educação" que "atua para facilitar a construçáo de uma Base de qualidade" buscou influenciar a definição de um currículo nacional, com apoio de vários grupos, nacionais e internacionais.

É relevante observar que a Estratégia (2.2), que diz respeito à BNCC inscrita no PNE (BRASIL, 2014), passou a ter prioridade nas políticas do governo federal ao longo do período de gestão de quatro ministros da educação, tal a força dos grupos que defendiam a BNCC dentro e fora do MEC. Além do mencionado Movimento pela Base, os mais ardorosos defensores encontravam-se no Movimento Todos pela Educação ${ }^{5}$, no Conselho Nacional dos Secretários de Educação (Consed) e na União dos Dirigentes Municipais de Educação (Undime) ${ }^{6}$.

É somente no governo Michel Temer que a dimensão conservadora da BNCC ganha maior expressão e se evidencia com mais nitidez seu elo com os PCNs, definidos durante a gestáo do Ministro da Educaçáo Paulo Renato no governo de Fernando Henrique Cardoso, e que receberam, à época, inúmeras críticas da comunidade acadêmica ${ }^{7}$.

De fato, o ministro Mendonça Filho alterou o processo de construção da terceira versão da BNCC, cuja metodologia de elaboração da primeira e da segunda versóes era de responsabilidade de um grupo de especialistas, vinculados às universidades, conforme mostram os documentos exarados pela Secretaria de Educação Básica (SEB) do MEC. Ele restringiu a participação desses especialistas ao instituir o Comitê Gestor da Base Nacional Comum Curricular e reforma do ensino médio (Portaria MEC no 790, de 27 de julho de 2016) para acompanhar o processo de discussão da segunda versão da $\mathrm{BNCC}$, encaminhar sua proposta final ao $\mathrm{CNE}$, bem como propor subsídios para a reforma do ensino médio. O comitê era coordenado pela secretária executiva Maria Helena Guimarães de Castro ${ }^{8}$, que ocupou esse mesmo cargo na gestão do ministro Paulo Renato, no governo FHC, quando os PCNs foram implementados.

É oportuno destacar, tendo em vista a análise da trajetória das políticas curriculares definidas em sucessivos governos, que a terceira versão da BNCC, sistematizada pelo Comitê Gestor do MEC, apresenta vários pontos de identidade com a visão de Castro (2008), tal como esta expóe em texto publicado em 2008, ou seja, uma década antes dessa consolidação:

Toda escola deveria incluir em seu projeto: 1) os valores básicos que seus alunos devem desenvolver, tais como sociabilidade, respeito às diferenças, ética, solidariedade e cooperação no trabalho em equipe; 2) as competências cognitivas que todos devem adquirir e as teorias de como aprender e como ensinar. Não pode haver uma única pedagogia. 3) as rotinas básicas da escola: uso do tempo escolar; monitoramento do aprendizado 
e uso dos resultados das avaliaçóes para melhorar o desempenho de todos os alunos. [...] O que nós queremos é ter uma proposta de orientação curricular que estabeleça os conteúdos que o aluno deve aprender em cada série ou ciclo, independente do livro didático, independente da abordagem pedagógica. $\mathrm{O}$ aluno será avaliado de acordo com as competências e habilidades estabelecidas para cada ciclo de aprendizagem. Nosso objetivo é estabelecer uma base curricular comum, um núcleo básico de aprendizagem, de conteúdos, competências e habilidades, que toda criança tem que aprender até o final do Ensino Fundamental (CASTRO, 2008).

Com efeito, é essa mesma perspectiva de política curricular que pode ser identificada em artigo da referida Secretária Executiva e Coordenadora do Comitê Gestor publicado em 11 de setembro de 2018, após a aprovação da BNCC no CNE:

\begin{abstract}
A BNCC explicita que as decisóes pedagógicas devem estar orientadas para o desenvolvimento de competências, com a indicação clara do que os alunos devem "saber" e, sobretudo, do que devem "saber fazer". Com isso, se estabelecem referências para o fortalecimento de açóes que assegurem as aprendizagens essenciais definidas na Base. Para atingir os objetivos a que se propóe, o documento está organizado em 10 competências gerais que deverão ser desenvolvidas por todos os alunos. Há ainda as competências específicas por áreas de conhecimento e pelos componentes curriculares do Ensino Fundamental (ANDRADE, 2018).
\end{abstract}

A terceira versão da BNCC (para alguns estudiosos, considerada a quarta, uma vez que a terceira versão entregue ao $\mathrm{CNE}$ foi, posteriormente, modificada) com alteraçóes apresentadas pelo MEC, foi votada e aprovada pelo CNE, após pedido de vistas de três conselheiras que se posicionaram contrariamente à referida versão (AGUIAR; DOURADO, 2018).

De acordo com críticos desse processo como Ximenes (2017 apud MACHADO, 2018), em entrevista à Fiocruz:

A base aprovada tem graves retrocessos, mesmo quando comparada às versóes anteriores, inclusive à $3^{\text {a }}$ versão. Ao final, temos um documento tecnocrático e conservador, produzido sem transparência e que tem a pretensão de ser imposto aos sistemas de ensino e às escolas, por diferentes técnicas já em desenvolvimento. É muito sintomático que o texto tenha sido aprovado contra a posição das principais associaçóes e entidades científicas do campo educacional, como Anfope [Associação Nacional pela Formação dos Profissionais da Educação], ANPed [Associação Nacional de Pós-Graduação e Pesquisa em Educação], Cedes [Centro de Estudos Educação 
e Sociedade], Forundir [Fórum Nacional de Diretores de Faculdades, Centros de Educaçáo e Equivalentes] e outras. Cabe perguntar então quem apoiou a aprovação com falhas e retrocessos como a instrumentalização do currículo pelo mercado educacional e avaliaçóes estandardizadas, censura em temas cruciais como racismo, sexualidade, homofobia e gênero e inclusáo de ensino religioso em todos os anos do ensino fundamental. A minha percepçáo é que, nesse estágio final de tramitação da BNCC, saiu-se vitoriosa uma macabra coalizão de interesses de mercado, com enorme capacidade de influência a partir dos institutos de bancos e empresas e suas assessorias educacionais, de reacionários do dito "Escola sem Partido", uma organizaçáo que promove a censura em todas as instâncias do debate educacional, e do campo religioso, que havia saído derrotado no julgamento do STF [Supremo Tribunal Federal] e que agora quer reverter a questáo em seu favor.

Esse capítulo da história recente da educaçáo brasileira mostra também que o conceito de Educação Básica (educação infantil, ensino fundamental e ensino médio), arduamente conquistado pela sociedade, sofreu uma ruptura no governo Michel Temer, ao ser excluído da BNCC o ensino médio. O CNE aprovou a terceira versão da BNCC da educação infantil e do ensino fundamental, apesar das manifestações contrárias das entidades científicas do campo educacional. Sobre o papel desempenhado pelo Conselho, nesse episódio, Ximenes (2017 apud MACHADO, 2018) verbaliza crítica presente nos debates entre especialistas:

O CNE se colocou numa posição cartorial e submissa desde o início. De cara, aceitou tramitar uma proposta de BNCC parcial, sem o ensino médio. Ou seja, exclui a possibilidade de produzir com autonomia um debate cuidadoso e com o tempo necessário e olhando para o conjunto da educação básica. Ainda que tenha adiado a votação, isso se deveu a um pedido de vista conjunto, e a reação da maioria dos conselheiros ao pedido de três conselheiras foi aprovar um descabido pedido de urgência. Houve um total desrespeito à prerrogativa das conselheiras em editoriais e notas furiosas patrocinadas pelos reformadores empresariais. O CNE também não atendeu ao pedido de discussão coletiva, de ao menos uma audiência pública adicional, feito pelas principais associações de pesquisa da área, como a Anped [Associação Nacional de Pós-Graduação e Pesquisa em Educação], a Associação de Formação de Professores. Isso é muito sintomático. Dado esse alinhamento aparente do CNE com a pressão dos institutos empresariais e o completo desalinhamento com essas associaçóes que reúnem os educadores e formadores de educadores, eu náo tinha nenhuma expectativa de correçáo de rumos nesse momento. 
Para justificar a aprovação da BNCC, um dos argumentos recorrentes utilizados pelo MEC e instituiçóes é que ela "foi construída coletivamente e em um processo democrático" e que a primeira versáo teria recebido mais de 12 milhōes de contribuiçóes durante consulta pública e que, em 2016, mais de 9 mil professores e gestores analisaram o documento?.

Contudo, os dados referentes à metodologia de construção da BNCC da educação infantil e do ensino fundamental foram questionados por Fernando Cássio (2017) em artigo publicado no site do jornal Nexo: "O impressionante número de 12 milhóes de "contribuiçóes" à consulta pública da Base, divulgado pelo MEC, é na verdade $8.400 \%$ maior do que o número de contribuintes". Esclarece o autor:

Uma análise dos microdados da consulta pública, obtidos da Secretaria Executiva do MEC via Lei de Acesso à Informação, mostra que o número de contribuintes únicos nas três categorias é 143.928. Dessa forma, dos mais de 300 mil cadastros evocados pelo ex-secretário Palácios em 2016, mais da metade não se converteu a contribuinte da consulta. Parece óbvio, portanto, que as 12 milhóes de contribuiçóes não significam 12 milhóes de contribuintes (CÁSSIO, 2017).

Com a aprovação da BNCC da educação infantil e do ensino fundamental pelo CNE, consolidou-se uma orientação hegemônica e padronizada de currículo nacional (MACEDO, 2018; MENDONÇA, 2018), cujas raízes são encontradas nas políticas educacionais do governo de Fernando Henrique Cardoso e que se desenvolveram, contraditoriamente, ao longo dos governos de Lula da Silva e Dilma Rousseff, especialmente, com a mediação do Consed, Undime e instituiçóes ${ }^{10}$ empresariais e privadas nacionais e internacionais. Finalmente, tomaram vulto no governo Temer, quando a BNCC se configurou como o eixo central das políticas nacionais de avaliação, currículo, gestão e formação dos professores.

Os efeitos dessas decisóes do MEC e do CNE contribuíram para aumentar as tensóes nos meios educacionais com o processo de reforma do ensino médio e a definiçáo de uma Base Nacional Comum do Ensino Médio, conforme discussão que segue.

\section{Mais uma vez uma reforma do ensino médio com estrutura dual}

A história da tramitação da Base Nacional Comum do Ensino Médio no $\mathrm{CNE}$ só será compreendida se reportada às medidas de políticas do governo Temer. O movimento mais impactante desse governo no plano nacional foi, reconhecidamente, a emissáo da PEC dos Gastos, que, aprovada pelo Congresso Nacional, como já mencionado, limitou o aumento dos gastos públicos à variação da 
inflação. É nesse contexto que o governo também emitiu uma Medida Provisória (MP 746/2016), posteriormente Lei no 13.415/2016, de 13 de fevereiro de 2017, promovendo a Reforma do Ensino Médio (LIMA; MACIEL, 2018; AMARAL, 2016; FERRETTI; SILVA, 2017; FERRETTI, 2018).

De acordo com o governo federal, o objetivo da reforma é tornar essa etapa do ensino mais dinâmica e atrativa aos jovens, tendo em vista a alta evasão entre os estudantes de 15 a 17 anos (1,3 milhão, segundo dados do IBGE). Mas, ao ser anunciada, mediante uma medida provisória, sem consultas às entidades da área, atropelando os projetos de lei sobre a matéria em tramitaçáo no Congresso Nacional e, também, interrompendo programas e açôes em andamento do governo anterior que visavam superar tal quadro, configurou-se como uma medida de cunho autoritário e conservador, o que motivou reações contrárias em vários setores da sociedade.

A questão mais problemática da reforma do ensino médio proposta diz respeito à segmentação da organicidade da educação básica (educação infantil, ensino fundamental e ensino médio) que sonega conhecimento aos estudantes das camadas populares que estudam nas escolas públicas, tendo em vista que são poucas as unidades escolares no país que dispóem, atualmente, de infraestrutura e condiçóes materiais adequadas e de um quadro de docentes e demais profissionais da educação necessários para dar sustentação à oferta escolar de cinco itinerários formativos a todos os estudantes (SILVA; SCHEIBE, 2017).

Para melhor compreensão da complexidade desses arranjos institucionais, de viés autoritário, e o papel desempenhado pelos diversos atores envolvidos, é preciso mencionar que, ao longo da sistematização da BNCC da educação infantil e do ensino fundamental, foi estabelecida uma estreita colaboração entre MEC e conselheiros da Comissão Bicameral da Base Nacional Comum Curricular ${ }^{11}$, do $\mathrm{CNE}$, com presenças constantes de assessores do MEC no apoio às atividades desenvolvidas pela referida Comissão, o que foi intensificado no processo referente à BNCC do ensino médio.

Entretanto, o contexto em que foi promulgada a Lei da Reforma do Ensino Médio e a forma apressada de condução do processo de construção da BNCC do ensino médio para responder aos ditames dessa Reforma, impactou a Comissão Bicameral da BNCC, o que resultou no pedido de afastamento da presidência do Conselheiro César Callegari, da Câmara de Educação Básica, conforme carta de renúncia apresentada ao CNE, a cujo teor a imprensa teve acesso e dela fez ampla cobertura.

Em sua carta-renúncia, o Conselheiro faz críticas às várias dimensões da BNCC do ensino médio, reiterando, inclusive, o teor de críticas anteriormente emitidas pelas Conselheiras do CNE, Márcia Angela da Silva Aguiar, Malvina Tuttman e Aurina Oliveira Santana, na ocasião da aprovação da BNCC da 
educação infantil e do ensino fundamental no CNE (BRASIL, 2017c). Afirma o Conselheiro Callegari no referido documento:

Não é possível separar a discussão da BNCC da discussão da Lei $n^{\circ} 13405$ que teve origem em Medida Provisória do Presidente da República e estabeleceu os fundamentos do que chamam de "reforma do ensino médio". Uma coisa está intrinsecamente ligada à outra $[. .$.$] .$

A proposta do MEC para o ensino médio não só destoa, mas contradiz em grande medida o que foi definido na BNCC das etapas educacionais anteriores e é radicalmente distinta do que vinha sendo cogitado nas versóes primeiras. Tinham, afinal, razão os que temiam rupturas e fragmentação da educação básica. [...]

Ao abandonar a atenção aos domínios conceituais próprios das diferentes disciplinas, a proposta do MEC não só dificulta uma visão interdisciplinar e contextualizada do mundo, mas pode levar à formação de uma geração de jovens pouco qualificados, acríticos, manipuláveis, incapazes de criar e condenados aos trabalhos mais simples e entediantes, cada vez mais raros e mal remunerados [...].

O atual governo diz que o "novo ensino médio" já teria sido aprovado pela maioria dos jovens. Não é verdade. Nenhuma mudança chegou às escolas e talvez para a maioria elas nunca cheguem. Alardeia a oferta de um leque de opçóes para serem escolhidas pelos estudantes, mas na sua BNCC náo indica absolutamente nada sobre o que esses "itinerários formativos" devem assegurar [...].

A nova Lei abre o ensino médio para que ele seja oferecido a distância. Nesse simulacro de educação, pacotes EAD poderão substituir professores e dispensar laboratórios e bibliotecas [...].

ais do que nunca, o CNE deve assumir seu papel de Órgão de Estado, guardião dos interesses educacionais da Naçáo e protetor da Educação contra os males das descontinuidades e dos oportunismos (apud BRASIL, 2017c, grifo nosso).

Esse rol de críticas emitidas na carta-renúncia do presidente da Comissão Bicameral da BNCC do ensino médio repercutiu no meio acadêmico, pois reforçava posiçóes assumidas pelas associaçóes científicas da área. Todavia, não teve maior ressonância no $\mathrm{CNE}$, a não ser da parte dos conselheiros que, desde o processo de aprovação da BNCC da educação infantil e do ensino fundamental, vinham se posicionando contrariamente à Base.

Com a renúncia do conselheiro Callegari, procedeu-se, de imediato, à sua substituição da presidência da Comissão, assumindo a função o presidente do CNE, 
conselheiro Eduardo Deschamps, com dois relatores: José Francisco Soares, da Câmara de Educação Básica, e Joaquim José Soares Neto, da Câmara de Educação Superior. Estes deram continuidade ao processo com intensa participação do MEC, até mesmo com a atuação direta do novo ministro da Educaçáo, Rossieli Soares da Silva, que, ao longo do governo Michel Temer, foi o titular da SEB e havia participado, como membro nato no CNE, do processo de definição da BNCC.

A BNCC foi aprovada após protestos de professores contrários ao documento elaborado pelo MEC e de cancelamento de audiência pública promovida pelo $\mathrm{CNE}$ sobre o tema. O conselheiro Callegari, ao ser indagado pela mídia sobre a separação da base da educação infantil e ensino fundamental e a base do ensino médio, foi enfático:

Essa separação, a meu ver, é feita para atender a outros interesses, principalmente o de abrir o Ensino Médio para ser operado também pela iniciativa privada, seja pela possibilidade que a própria Lei traz dos recursos da etapa, inclusive do Fundeb, serem utilizados por empresas ou instituiçóes privadas, como é o caso do Senai, do Senac, como também pela possível comercialização de pacotes de educação a distância em escolas públicas e privadas. No meu modo de entender esse interesse recôndito agora ganha visibilidade por tudo aquilo que se apresenta na proposta da Base e no desenvolvimento da Lei do Ensino Médio também (CALLEGARI apud BASILIO, 2018).

Contudo, para a instituição das duas bases nos sistemas de ensino e escolas brasileiras têm sido fundamentais as iniciativas e os apoios dados, sobretudo pelo Consed e pela Undime, instâncias representativas dos titulares das secretarias de educação dos estados e municípios, respectivamente. Aliás, o relacionamento entre essas instâncias e o CNE aprofundou-se com a presença direta dos presidentes desses respectivos órgãos, na condição de conselheiros titulares, no Conselho Nacional de Educação.

Vale ressaltar que, quando o ministro Aloizio Mercadante deixou o Ministério da Educação, em decorrência do processo de impeachment da presidenta Dilma Rousseff, a segunda versão da BNCC, ainda inacabada, foi apresentada ao CNE e se solicitou ao Consed e à Undime que dessem prosseguimento às audiências previstas com professores e gestores dos estados atinentes a essa segunda versão.

De outro lado, é deveras importante assinalar que, em todas as manifestaçóes oficiais sobre a BNCC da educação infantil e ensino fundamental e da BNCC do ensino médio, são atribuídas grandes responsabilidades aos professores por sua implementação no chão da escola, o que per se justificaria, do ponto de vista dos dirigentes do MEC, a formulação de uma base correlata, ou seja uma base específica para formação de professores. 
Essa proposta começou a evoluir na Secretaria Executiva do Ministério, com iniciativas da secretária executiva Maria Helena Guimaráes, sem que secretarias do MEC tivessem tomado as medidas necessárias junto às instituiçóes de ensino superior do país para acompanhar a implementação da Resolução CNE $n^{\circ}$ 2/2015 (BRASIL, 2015), aprovada pelo Conselho, e que foi resultado de um amplo processo de debate com a área e com setores do ministério.

Pode explicar esse tipo de opção política o fato de que no grupo que chega ao MEC, na gestão de Michel Temer, há profissionais (assessores de projetos, consultores, conselheiros, leitores críticos, entre outros) que estiveram de alguma forma envolvidos no processo de definição das Diretrizes Curriculares da Educação Básica e dos Parâmetros Curriculares Nacionais do período do Governo $\mathrm{FHC}^{12}$ e que passam a atuar em sua interlocução com o CNE para retomar o fio condutor daquelas proposiçóes do fim da década de 1990.

Com efeito, o único obstáculo que se interpóe a esse propósito é a existência da Resoluçáo CNE/CP no 2/2015, de $1^{\circ}$ de julho de 2015, que define as Diretrizes Curriculares Nacionais para a formação inicial em nível superior (cursos de licenciatura, cursos de formaçáo pedagógica para graduados e cursos de segunda licenciatura) e para a formação continuada do magistério da educação básica e que se encontra em processo de implementação nos cursos de formação de professores do país.

Nesse sentido, a Secretaria Executiva do Ministério da Educação busca estabelecer uma interação com o CNE, demonstrando que o MEC tem uma nova agenda para a formação de professores. Todavia, essa pauta não teve desdobramentos na Comissão Bicameral de Formação de Professores presidida pela conselheira Malvina Tuttman, da Câmara de Educação Básica, tendo em vista que a prioridade do debate tinha como foco as questôes apresentadas pelas instituiçóes de ensino superior relacionadas à implementação da Resolução CNE no 2/2015.

Entretanto, ao apagar das luzes do governo Michel Temer e com o término de mandatos de Conselheiros que participaram do debate e da construção da Resolução CNE/CP no 2/2015, o MEC entregou ao Conselho, em 13 de dezembro de 2018, uma proposta de reformulaçáo dos cursos de licenciatura, denominada de Base Nacional Comum de Formação de Professores da Educação Básica (BRASIL, 2018b), sem que houvesse prévia interação com a comunidade acadêmica.

A forma impositiva de conduzir essa política desencadeou, de imediato, reaçóes das principais entidades educacionais da área. A Associação Nacional pela Formação dos Profissionais da Educação (Anfope) e o Fórum Nacional de Diretores de Faculdades/Centros/Departamentos de Educação ou Equivalentes das Universidades Públicas Brasileiras (Forumdir) foram os primeiros a manifestar, publicamente, posição contrária à proposta, afirmando que a referida Base 
não estabelece qualquer diálogo com as instituiçóes formadoras, em especial com as faculdades de educação das Universidades públicas e com os programas de pós-graduaçáo em educação, desprezando o conhecimento científico produzido no país sobre a formação dos professores e sobre a escola básica brasileira, assim como o faz com as entidades acadêmicas do campo educacional, as entidades representativas dos professores e estudantes (ANPED, 2018).

Entretanto, para o então ministro da Educação, Rossieli Soares Silva, "a proposta de base apresentada pelo MEC pretende revisar as diretrizes dos cursos de pedagogia e das licenciaturas para colocar foco na prática da sala de aula, no conhecimento pedagógico do conteúdo e nas competências previstas na BNCC da Educação Básica" (apud BRASIL, 2018a). O posicionamento do ministro da Educação revela, mais uma vez, a centralidade atribuída à BNCC para a condução da política educacional do governo.

Ao tomar esse rumo, o MEC busca, de um lado, desconstruir uma normativa consolidada pelo CNE sobre a formação dos profissionais do magistério, que se configurou na Resolução CNE/CP no 2/2015, homologada em 25 de junho de 2015 (Diário Oficial da União de 25 de junho de 2015, seção 1, p. 13), após intensa interlocução com os setores do governo e da sociedade civil envolvidos com a temática. De outro lado, visa influenciar as instituiçôes de ensino superior responsáveis pela formação de professores da educaçáo básica para a aceitaçáo dos pressupostos das duas BNCC como guias inquestionáveis das políticas curriculares dos cursos de licenciatura em todas as áreas.

Com essa ação, fecha-se o ciclo iniciado no governo Fernando Henrique Cardoso com as políticas que instituíram os PCNs, cujos pressupostos assumidos por vários atores perpassaram diferentes governos. Simultaneamente, abre-se um novo ciclo com iniciativas do MEC requerendo o empenho dos gestores dos sistemas de ensino para que o ideário de formação do homem produtivo, na perspectiva neoliberal da educação, seja materializado no chão da escola.

\section{Considerações finais}

Desde o período do governo de Fernando Henrique Cardoso, efetiva-se uma orientaçâo política para o campo educacional, influenciada, sobretudo, por organismos internacionais e instituiçôes privadas com interesses alinhados às demandas do mercado. Tal perspectiva expressa-se com mais clareza nas medidas governamentais direcionadas à educação básica e à educação superior, especialmente às políticas curriculares, gestão educacional, avaliação e formação de profissionais da educação . 
Nesses campos, evidenciam-se os princípios basilares dos projetos educacionais em disputa na sociedade brasileira. Na perspectiva neoliberal, a ênfase situa-se na padronizaçáo dos currículos escolares e nos processos formativos assentados nos princípios da flexibilização, da eficiência, da eficácia, da meritocracia e da gestão de resultados. Na perspectiva de uma educação emancipadora, os princípios traduzem uma formação crítica e de aperfeiçoamento contínuo do ser humano. No limite, são essas perspectivas que subjazem à atuação das instituiçóes e dos atores sociais que disputam a primazia com relação à materialização das políticas públicas de educação.

O trajeto da construção e da aprovação da BNCC, tanto a da educação infantil e ensino fundamental (BRASIL, 2017c), quanto a do ensino médio (BRASIL, 2018), que promoveu a BNCC como eixo das políticas educacionais nos governos recentes, evidencia a capacidade de articulaçáo e de influência dos citados atores sociais nos diversos contextos, em busca de protagonismo nos processos.

Essas disputas de projetos não estão apenas no campo político-partidário, mas perpassam as esferas administrativas centrais da máquina pública que dialogam com as instituiçóes escolares, refletindo orientaçóes que assumem significados contraditórios no chão da escola. Nesses âmbitos, a efetivação de processos formativos dos profissionais da educaçáo constitui uma arena em que os projetos em disputa mostram a medida de seu protagonismo e o alcance das açôes desencadeadas nos variados espaços institucionalizados.

Nesse sentido, pode-se constatar, especialmente com o governo de Fernando Henrique Cardoso, a ação permanente no aparelho do Estado de vários atores que atuam, de forma ostensiva ou dissimulada, como verdadeiros guardióes dos princípios neoliberais que buscam instaurar como base de políticas e açôes dos sucessivos governos. No campo educacional essa atuação é expressiva, tendo em vista os recursos de poder que determinados atores possuem.

Considerando o PNE como uma projeção de propósitos, objetivos e metas que traduzem princípios educacionais consagrados na Constituição Federal (BRASIL, 1988) e materializados ou não em políticas públicas, torna-se possível analisar a açáo dos governos e dos grupos organizados da sociedade civil na efetivação desse plano.

Como visto, o PNE 2014-2024 somente foi aprovado pelo Congresso Nacional e homologado sem sanções pela presidenta Dilma Rousseff, em 2014. Esse Plano, que passou por múltiplas mediaçóes, tanto no MEC quanto no Congresso Nacional, onde tramitou durante quatro anos, apresenta muitos avanços com relação ao anterior (BRASIL, 2001), ao mesmo tempo que traz proposiçóes polêmicas e controvertidas. Uma dessas questóes, objeto de controvérsias, é a estratégia inscrita no PNE que remete à instituição de uma base nacional comum curricular, que deu amparo legal ao MEC para definir 
políticas com um viés homogeneizador para os currículos, a avaliação, a gestão e a formação de professores, contrariando, assim, a perspectiva construída, ao longo do debate educacional de uma base comum nacional que se expressasse por princípios gerais.

Todavia, a oportunidade para que o ideário neoliberal nas políticas educacionais avançasse de patamar ocorreu, de fato, na gestão do presidente Michel Temer, que assumiu a presidência com o impedimento da presidenta Dilma Rousseff. Portador de uma agenda restritiva, o governo aprofundou o ajuste fiscal, mesmo em um contexto de elevado desemprego, promoveu reformas com o propósito de conter os gastos sociais e favoreceu o capital rentista. Foram atingidos investimentos públicos nas áreas de saúde, educação, assistência social, entre outros. O impacto da PEC dos Gastos na educação atingiu, sobretudo, as metas do PNE 2014-2024 que requerem mais investimentos, comprometendo direitos sociais garantidos pela Constituição de 1988.

Ao mesmo tempo, ocorreram mudanças na estrutura do MEC e foram redirecionadas as políticas educacionais, com novas ênfases nas políticas curriculares, de avaliação e de formação de profissionais da educação, com apoios explícitos do Consed, Undime, Movimento pela Base, e de outros atores. O processo de construçáo da Base Nacional Comum Curricular foi alterado com a instituição, no MEC, do Comitê Gestor encarregado de consolidar a terceira versão da base.

Os atores defensores do estabelecimento de uma base nacional comum curricular logo a viram como a possibilidade aberta pelo governo Temer para retornar com primazia ao jogo político que impulsiona as decisóes relativas às políticas educacionais. É nesse contexto que tomam maior fôlego movimentos de caráter conservador, que buscam influenciar as políticas educacionais e contribuir para a sua materialização nas redes e sistemas de ensino da educação básica.

Evidencia-se, assim, a continuidade de uma visão de educação e de formação humana que é assumida, contraditoriamente, por governos com posiçōes distintas ou antagônicas, sendo expressa nas normativas que objetivam moldar a formação de crianças e jovens por meio de uma ação dirigida dos sistemas centrais de educação e de ensino-aprendizagem às instituições educativas.

A BNCC portanto, como chave principal para mudar ou aprofundar os padrōes concernentes ao currículo, avaliação, gestão e formação de professores da educação básica e superior no Brasil apresenta-se como uma estratégia dirigida à "formação do "cidadão produtivo" assujeitado à lógica mercantil" em detrimento da "construção de um sujeito emancipado" (FRIGOTTO; CIAVATTA, 2006, p. 17-18).

Contudo, como a história é construída nas relaçóes conflituosas entre grupos e classes sociais de interesses distintos, novos rumos para as políticas educacionais atuais poderão emergir. Rumos instituídos em decorrência de eventuais 
mudanças conjunturais que afirmem a democracia no país e, com a atuação dos setores da sociedade civil organizada, que, imbuídos de uma visão republicana da educação nacional, avancem nos caminhos trilhados tendo como horizonte a superação das desigualdades sociais e educacionais, a afirmação de uma cidadania plena e a formação de cidadãos emancipados. Como diz Paulo Freire (1997, p. 155), o patrono da educação brasileira: "Ninguém caminha sem aprender a caminhar, sem aprender a fazer o caminho caminhando, refazendo e retocando o sonho pelo qual se pôs a caminhar".

\section{Notas}

1. Considerando que o artigo não se propóe a fazer uma análise ampla da atuação do governo FHC no setor educacional, remete-se à leitura dos textos de vários estudiosos que têm desenvolvido análises relevantes como Saviani (1997), Monlevade e Ferreira (1997), Melchior (1997), Davies (1998), Dourado (1999), Pinto (2000), Oliveira e Adriāo (2001), entre outros.

2. Ver: Brasil (2014).

3. Dilma Rousseff integrou o Governo Luiz Inácio Lula da Silva como ministra de Minas e Energia e, posteriormente, ministra-chefe da Casa Civil do Brasil.

4. Consultar a página: <http://movimentopelabase.org.br/quem-somos/>. Acesso em: 20 de maio de 2019.

5. Conforme Senna (apud CÂMARA DOS DEPUTADOS, 2014), "o movimento Todos pela Educação reúne como mantenedores institutos e fundaçôes privadas empresariais que se preocupam com a escolaridade da população e a melhoria da qualidade da mão de obra, insatisfatória para as necessidades do mercado. São seus mantenedores: Fundação Itaú Social, Fundação Bradesco, Fundaçâo Telefônica, Gerdau, Instituto Camargo Correa, Instituto Unibanco, Itaú BBA, Santander, Suzano, Fundação Lemann, Instituto Península, DPachoal. Entre seus parceiros figuram Fundação Santillana, Instituto Ayrton Senna, Fundação Victor Civita, McKinsey \& Company, Instituto Natura, Saraiva, Banco Interamericano de Desenvolvimento (BID)”.

6. Vide: Aguiar e Dourado (2018).

7. Vide: Moreira (1996).

8. Em 2014, matéria publicada no site da Fundação Porvir, que destacava que a base teria "respaldo em representantes de diferentes pontos do espectro político-partidário", informava que, "para Maria Helena Guimarães de Castro, diretora executiva da Fundação Sistema Estadual de Análise de Dados (Seade) de São Paulo e coordenadora do programa de educação do candidato à presidência Aécio Neves (PSDB), a ausência de uma Base Nacional é responsável por uma série de desencontros no processo educativo brasileiro" (LENOIR, 2014).

9. Vide: <http://movimentopelabase.org.br/acontece/base-entregue-cne/ $>$. Acesso em: 20 de maio de 2019 
10. A respeito do papel dessas instituiçóes, consultar: Avelar e Ball (2019).

11. Anteriormente, havia no CNE, uma Comissão Bicameral da Base Nacional Comum, que estava acompanhando a discussão da Base. Com a mudança da composição do CNE, na gestão do ministro da Educação Mendonça Filho, foi recomposta a Comissão Bicameral com mudanças de presidência e relatoria, alterando-se a sua própria denominação, com o acréscimo do termo "curricular".

12. A exemplo de professores e especialistas Guiomar Namo de Mello, Regina Alcântara de Assis, Kátia Smole, entre outros.

\section{Referências}

ADRIÃO, T.; PERONI, V. A formação das novas gerações como campo para negócios? In: AGUIAR, M. A. S.; DOURADO, L. F. (orgs.). A BNCC na contramáo do PNE 20142024: avaliação e perspectivas. Recife: ANPAE, 2018.

AFONSO, A. Reforma do estado e políticas educacionais: entre a crise do estado-nação e a emergência da regulação supranacional. Educaçáo \& Sociedade, v. 22, n. 75, p. 15-32, ago. 2001. http://dx.doi.org/10.1590/S0101-73302001000200003

AGUIAR, M. A. S. Política Educacional e a Base Nacional Comum Curricular: o processo de formulação em questão. Currículo sem Fronteiras, v. 18, n. 3, p. 722-738, set./dez. 2018.

AGUIAR, M. A. S.; DOURADO, L. F. (orgs.). A BNCC na contramão do PNE 20142024: avaliação e perspectivas. Recife: ANPAE, 2018. Disponível em: <http://www. anpae.org.br/BibliotecaVirtual/4-Publicacoes/BNCC-VERSAO-FINAL.pdf >. Acesso em: 20 maio 2019.

AMARAL, N. C. PEC 241/55: a "morte" do PNE (2014-2024) e o poder de diminuição dos recursos educacionais. Revista Brasileira de Política e Administraçáo da Educaçáo, Goiânia, v. 32, n. 3, p. 653-673, set./dez. 2016. https://doi.org/10.21573/ vol32n32016.70262

ANDERSON, P. Balanço do Neoliberalismo. In: SADER, E. (org.). Pós-neoliberalismo: as políticas sociais e o Estado democrático. São Paulo: Paz e Terra, 1995.

ANDRADE, M. H. G. BNCC - Desafios e oportunidades. Conexia Educaçáo, 2018. Disponível em: <https://conexiaeducacao.com.br/wp/blog/bncc/>. Acesso em: 21 maio 2019.

ASSOCIAÇÃO NACIONAL DE PÓS-GRADUAÇÃO E PESQUISA EM EDUCAÇÃO (ANPED). Manifesto Anfope em defesa da Formação de Professores. ANPED, 2018. Disponível em: <http://www.anped.org.br/news/manifesto-anfope-em-defesa-daformacao-de-professores $>$. Acesso em: $20 \mathrm{dez} .2018$.

AVELAR, M.; BALL, S. J. Mapping new philanthropy and the heterarchical state: The Mobilization for the National Learning Standards in Brazil. International Journal of Educational Development, v. 64, p. 65-73, 2019. Disponível em: <https://www. sciencedirect.com/science/article/pii/S0738059317302080?via\%3Dihub >. Acesso em: 20 maio 2019. https://doi.org/10.1016/j.ijedudev.2017.09.007 
BALL, S. J. Reformar escolas/reformar professores e os terrores da performatividade. Revista Portuguesa de Educaçáo, v. 15, n. 2, p. 3-23, 2002.

BASILIO, A. L. "Reforma do ensino médio vai acirrar desigualdades educacionais e sociais", diz Callegari. Carta Capital, 2018. Disponível em: <http://www.cartaeducacao. com.br/entrevistas/reforma-do-ensino-medio-vai-acirrar-desigualdades-educacionais-esociais-diz-callegari/>. Acesso em: 20 maio 2019.

BERNARDI, L. M.; UCZAK, L. H.; ROSSI, A. J. Relaçôes do Movimento Empresarial na política educacional brasileira: a discussão da Base Nacional Comum. Currículo sem Fronteiras, v. 18, n. 1, p. 29-51, jan./abr. 2018.

BORON, A. A. Estado, Capitalismo e Democracia na América Latina. São Paulo: Paz e Terra, 1994.

BRASIL. Conselho Nacional de Educação. Conselho Pleno. Resolução no 2, de $1^{\circ}$ de julho de 2015. Define as Diretrizes Curriculares Nacionais para a formaçáo inicial em nível superior (cursos de licenciatura, cursos de formação pedagógica para graduados e cursos de segunda licenciatura) e para a formação continuada. Brasília, 2015. Disponível em: $<\underline{\text { http:// }}$ portal.mec.gov.br/index.php?option=com docman\&view=download\&alias=70431-rescne-cp-002-03072015-pdf\&category slug=agosto-2017-pdf\&Itemid=30192 >. Acesso em: 20 fev. 2019.

BRASIL. Conselho Nacional de Educação. Conselho Pleno. Resoluçáo no 4, de 17 de dezembro de 2018. Institui a Base Nacional Comum Curricular na Etapa do Ensino Médio (BNCC-EM), como etapa final da Educação Básica, nos termos do artigo 35 da LDB, completando o conjunto constituído pela BNCC da Educação Infantil e do Ensino Fundamental, com base na Resolução CNE/CP no 2/2017, fundamentada no Parecer CNE/CP no 15/2017. Brasília, 2018.

BRASIL. Constituiçáo da República Federativa do Brasil. Brasília: Senado Federal, 1988.

BRASIL. Emenda Constitucional no 95, de 15 de dezembro de 2016. Brasília: Ministério da Educação, 2016. Disponível em: <http://www.planalto.gov.br/ccivil 03/ constituicao/emendas/emc/emc95.htm>. Acesso em: 20 abr. 2018.

BRASIL. Lei no 9.394/96. Estabelece as Diretrizes e Bases da Educação Nacional. Diário Oficial da República Federativa do Brasil, Brasília, 23 dez. 1996.

BRASIL. Lei no 10.172, de 9/1/2001. Estabelece o Plano Nacional de Educação. Diário Oficial da União, Brasília, 10 jan. 2001.

BRASIL. Ministério da Cidadania. Prêmio da FAO reconhece resultados do Brasil no combate à fome. Brasil: Ministério da Cidadania, 2014. Disponível em: <http://mds.gov. br/area-de-imprensa/noticias/2014/novembro/premio-da-fao-reconhece-resultados-dobrasil-no-combate-a-fome >. Acesso em: 19 maio 2019.

BRASIL. Ministério da Educação. Base Nacional para formaçáo do professor vai revisar cursos para conhecimento e valorizaçáo. Brasil: Ministério da Educação, 2018a. Disponível em: <http://portal.mec.gov.br/component/content/article?id=71951 > . Acesso em: 30 jul. 2019. 
BRASIL. Ministério da Educação. Formaçáo de professores será norteada pelas regras da BNCC. Brasil: Ministério da Educação, 2018b. Disponível em: < http://portal.mec.gov. br/component/content/article/211-noticias/218175739/72141-formacao-de-professoressera-norteada-pelas-regras-da-bncc?Itemid=164>. Acesso em: 20 mar. 2019.

BRASIL. Ministério da Educação. Portaria no 577, de 27 de abril de 2017. Dispóe sobre o Fórum Nacional de Educação. Brasília: Ministério da Educação, 2017a. Disponível em: <http://www.lex.com.br/legis 27402353 PORTARIA N 577 DE 27 DE ABRIL DE 2017.aspx>. Acesso em: 20 maio 2018.

BRASIL. Ministério da Educação. Secretaria de Educação Básica. Base Nacional Comum Curricular: educação é a base. Brasília: Ministério da Educação, 2017b.

BRASIL. Parecer CNE/CP 15/2017. Portaria no 1.570. Diário Oficial da União, seção 1, p. 146, $21 \mathrm{dez}$. 2017c.

BRESSER PEREIRA, L. C. A reforma do Estado nos anos 90: lógica e mecanismos de controle. Lua Nova: Revista de Cultura e Política, n. 45, p. 49-95, 1998. http://dx.doi. org/10.1590/S0102-64451998000300004

CÂMARA DOS DEPUTADOS. Plano Nacional de Educaçáo 2014-2024. Brasília: Centro de Documentação e Informação, 2014. Disponível em: <http://www.proec.ufpr.br/ download/extensao/2016/creditacao/PNE\%202014-2024.pdf>. Acesso em: 10 dez. 2018.

CÂMARA DOS DEPUTADOS. Promulgada emenda constitucional do teto dos gastos públicos. 2016. Disponível em: <https://www2.camara.leg.br/camaranoticias/ noticias/ECONOMIA/521413-PROMULGADA-EMENDA-CONSTITUCIONALDO-TETO-DOS-GASTOS-PUBLICOS.html>. Acesso em: 10 dez. 2018.

CARDOSO, F. H. Notas sobre a reforma do Estado. Novos Estudos/CEBRAP, n. 50, 1998.

CÁSSIO, F. Participação e Participacionismo na construção da Base Nacional Comum Curricular. Nexo, 2017. Disponível em: <https://www.nexojornal.com.br/ensaio/2017/ Participa\%C3\%A7\%C3\%A3o-e-participacionismo-na-constru\%C3\%A7\%C3\%A3oda-Base-Nacional-Comum-Curricular?utm source=socialbttns $>$. Acesso em: 4 fev. 2018.

CASTRO, M. H. G. de. Problemas institucionais do ensino público. Braudel Papers, 2008. Disponível em: <http://pt.braudel.org.br/publicacoes/braudel-papers/downloads/ portugues/bp42 pt.pdf >. Acesso em: 19 maio 2019.

CURY, C. R. J. Reflexóes sobre a construçáo do Sistema Nacional Articulado de Educaçáo e o Plano Nacional de Educaçáo: diretrizes e estratégias de açáo. Brasília: Inep, 2009.

DALE, R. A sociologia da educação e o Estado após a globalização. Educação e Sociedade, Campinas, v. 31, n. 113, p. 1099-1120, out.-dez. 2010. http://dx.doi.org/10.1590/ $\underline{\text { S0101-73302010000400003 }}$

DAVIES, N. O Fundef e o orçamento da educaçáo: desvendando a caixa preta. Niterói: Xamã, 1998.

DIAS SOBRINHO, J. Universidade e avaliação: entre a ética e o mercado. Florianópolis: Insular, 2002. 
DOURADO, L. F. Plano Nacional de Educaçáo: o epicentro das políticas de estado para a educação brasileira. Goiânia: Editora da Imprensa Universitária/ANPAE, 2017.

DOURADO, L. F; OLIVEIRA, J. F. de. Base Nacional Comum Curricular (BNCC) e os impactos nas políticas de regulação e avaliação da educação superior. In: AGUIAR, M. A. S.; DOURADO, L. F. (orgs.). A BNCC na contramão do PNE 2014-2024: avaliação e perspectivas. Recife: ANPAE, 2018.

DOURADO, L. F. Financiamento da Educação Básica. Goiânia: Autores Associados/ Cegraf/UFG, 1999.

FERRETTI, C. J. A reforma do Ensino Médio e sua questionável concepção de qualidade da educação. Estudos Avançados, São Paulo, v. 32, n. 93, 2018. http://dx.doi. org/10.5935/0103-4014.20180028

FERRETTI, C. J.; SILVA, M. R. Reforma do ensino médio no contexto da Medida Provisória no 746/2016: Estado, currículo e disputas por hegemonia. Educaçáo e Sociedade, Campinas, v. 38, n. 139, p. 385-404, abr.-jun. 2017. http://dx.doi. org/10.1590/es0101-73302017176607

FÓRUM NACIONAL POPULAR DE EDUCAÇÃO (FNPE). Documento Final Plano de Lutas. CONAPE, 2018. Disponível em: <http://fnpe.com.br/docs/documentos/docsconferencia/fnpe-conape2018-documento-final-planodelutas.pdf $>$. Acesso em: 20 maio 2019.

FREIRE, P. Pedagogia da esperança. São Paulo: Paz e Terra, 1997.

FREITAS, L. C. Os Reformadores Empresariais da Educação e a disputa pelo controle do processo pedagógico na escola. Educaçáo e Sociedade, Campinas, v. 35, n. 129, p. 1085 1114, out.-dez. 2014. http://dx.doi.org/10.1590/ES0101-73302014143817

FRIGOTTO, G.; CIAVATTA, M. (orgs.). A formaçáo do cidadáo produtivo: a cultura de mercado no ensino médio técnico. Brasília: Instituto Nacional de Estudos e Pesquisas Educacionais Anísio Teixeira, 2006.

GRACINDO, R. V. O Sistema Nacional de Educação e a escola pública de qualidade para todos. Retratos da Escola, Brasília, v. 4, n. 6, p. 53-64, jan.-jul. 2010.

INSTITUTO BRASILEIRO DE GEOGRAFIA E ESTATÍSTICA (IBGE). PNAD Contínua 2017: número de jovens que não estudam nem trabalham ou se qualificam cresce 5,9\% em um ano. 2018. Disponível em: <https://agenciadenoticias.ibge.gov.br/ agencia-sala-de-imprensa/2013-agencia-de-noticias/releases/21253-pnad-continua-2017numero-de-jovens-que-nao-estudam-nem-trabalham-ou-se-qualificam-cresce-5-9-emum-ano>. Acesso em: 16 out. 2019.

PINTO, J. M. R. Os Recursos para educaçáo no Brasil no contexto das finanças públicas. Brasília: Plano, 2000.

POCHMANN, M. Estado e capitalismo no Brasil. Educação e Sociedade, Campinas, v. 38, n. 139, p. 309-330, abr.-jun. 2017. http://dx.doi.org/10.1590/es0101-73302017176603

SANTOS, B. de S. A globalizaçáo e as ciências sociais. São Paulo: Cortez, 2002. 
SAVIANI, D. A nova lei da educação: trajetórias, limites e perspectivas. São Paulo: Autores Associados, 1997.

SAVIANI, D. Política educacional no Brasil após a ditadura militar. Revista HISTEDBR On-line, Campinas, v. 18, n. 2 [76], p. 291-304, abr./jun. 2018. http://dx.doi. org/10.20396/rho.v18i2.8652795

SILVA, M. R.; SCHEIBE, L. Reforma do ensino médio: Pragmatismo e lógica mercantil. Retratos da Escola, Brasília, v. 11, n. 20, p. 19-31, jan./jun. 2017. http://dx.doi. org/10.22420/rde.v11i20.769

LENOIR, C. Uma base comum para garantir aprendizado a todos. Porvir, 2014. Disponível em: <http://porvir.org/uma-base-comum-para-garantir-aprendizado-todos/>. Acesso em: 3 maio 2019.

LIMA, M.; MACIEL, S. L. A reforma do Ensino Médio do governo Temer: corrosão do direito à educação no contexto de crise do capital no Brasil. Revista Brasileira de Educaçáo, Rio de Janeiro, v. 23, 2018. http://dx.doi.org/10.1590/s1413$\underline{24782018230058}$

MACEDO, E. "A base é a base". E o currículo o que é? In: AGUIAR, M. A. S.; DOURADO, L. F. (orgs.). A BNCC na contramáo do PNE 2014-2024: avaliação e perspectivas. Recife: ANPAE, 2018.

MACHADO, K. Entrevista: Salomão Ximenes. "Temos um documento tecnocrático e conservador, produzido sem transparência”. Fiocruz, 2018. Disponível em: <http://www. epsjv.fiocruz.br/noticias/entrevista/temos-um-documento-tecnocratico-e-conservadorproduzido-sem-transparencia>. Acesso em: 19 maio 2019.

MENDONÇA, E. F. PNE e Base Nacional Comum Curricular (BNCC): impactos na gestão da educação e da escola. In: AGUIAR, M. A. S.; DOURADO, L. F. (orgs.). A BNCC na contramáo do PNE 2014-2024: avaliação e perspectivas. Recife: ANPAE, 2018.

MELCHIOR, J. C. A. Mudanças no financiamento da educaçáo no Brasil. Campinas: Autores Associados, 1997.

MONLEVADE, J.; FERREIRA, E. O Fundef e seus pecados capitais. Ceilândia: Ideia, 1997.

MOREIRA, A. F. B. Os Parâmetros Curriculares Nacionais em questão. Educaçáo e Realidade, v. 21, n. 1, p. 9-22, jan./jun. 1996.

NASSIF, L. Neoliberalismo do governo Temer trouxe a nova segregação social, por Marcio Pochmann. GGN, 2018. Disponível em: <https://jornalggn.com.br/artigos/ neoliberalismo-do-governo-temer-trouxe-a-nova-segregacao-social-por-marciopochmann/>. Acesso em: 12 abr. 2019.

OLIVEIRA, R. P. de; ADRIĀO, T. (orgs.). Gestáo, financiamento e direito à educaçáo. Análise da LDB e Constituição Federal. São Paulo: Xamã, 2001.

PINTO, J. M. R. Financiamento da educação no brasil: um balanço do governo FHC (1995-2002). Educaçáo e Sociedade, Campinas, v. 23, n. 80, p. 108-135, set. 2002. http://dx.doi.org/10.1590/S0101-73302002008000008 


\section{SOBRE A AUTORA}

Márcia Angela da Silva Aguiar é professora titular da Universidade Federal de Pernambuco (UFPE), doutora em Educação pela Universidade de São Paulo (USP), exConselheira da Câmara de Educação Superior do Conselho Nacional de Educação (20152018), coordenadora do Observatório de Políticas e Gestão da Educação do Programa de Pós-Graduação em Educação (PPGE)/Centro de Educação/UFPE.

Recebido em 17 de junho de 2019.

Aceito em 09 de setembro de 2019. 